\title{
Malandragem e "outra cidade": representações do Rio de Janeiro nas histórias em quadrinhos do Zé Carioca
}

\author{
Mário Sérgio Ignácio Brum ${ }^{1}$
}

Resumo: Esse artigo trata das representações sociais sobre a cidade do Rio, especificamente sobre sua população mais pobre, que habita os morros e periferias da cidade, a partir das histórias em quadrinhos do "Zé Carioca", personagem dos Estúdios Disney. Para tal, analisamos toda a trajetória de criação e produção do personagem, desde a sua origem dentro do programa de intercâmbio cultural entre Brasil e Estados Unidos na década de 1940, passando pelas diversas fases de publicação dos quadrinhos no Brasil com foco principalmente na produção da década de 1970 em que as visões sobre os hábitos e os cenários do personagem, arquétipo do malandro carioca, são refletidas nas histórias de alcance nacional, que nos servem de exemplo das representações sociais e do universo cultural do período e, dentro dele, do lugar das favelas, da cidade do Rio e dos mais pobres nele, no que analisaremos também algumas visões sobre as favelas e a cidade do Rio.

Palavras-chave: Zé Carioca, Histórias em Quadrinhos, Representações Sociais. Malandro.

\section{Rascality and "another city": representations of Rio de Janeiro in Zé Carioca's Comics}

Abstract: This article deals with the social representations on the city of Rio, specifically about its poorer population, which inhabits the hills and outskirts periphery of the city, coming from the comic books of "Zé Carioca", character of Disney Studios. Up this far we are able to analyze the whole trajectory of the creation and production of the character, since its beginning within the cultural exchange program between Brazil and the United States in back in the 1940s, passing through the several phases of comic books published in Brazil focusing mainly on the production of $70 \mathrm{~s}$, when the visions about the habits and scenarios of the character, archetype of the carioca(Rio living guy) trickster, are reflected in the national scope stories, which it serve as an example of the social representations and cultural universe of the period and, within it, the place of the favelas, the city of Rio and the place of poorest in it, in which we will also analyze some views on the favelas and of the city of Rio.

Key-words: Zé Carioca, Comic books, Social Representation, Scallywag.

\footnotetext{
${ }^{1}$ Instituto Nacional de Ciência e Tecnologia (INCT), Rio de Janeiro, RJ, Brasil. mariobrum@yahoo.com.br.
} 
Trataremos nesse paper das representações da cidade do Rio de Janeiro e do cotidiano do morador da cidade, particularmente dos mais pobres, através das histórias em quadrinhos (HQs) do Zé Carioca, personagem criado pelo estadunidense Walt Disney durante visita ao Brasil no começo da década de 1940, dentro da Política de Boa Vizinhança promovida pelo governo dos Estados Unidos como forma de angariar simpatia da América Latina para alianças no esforço da II Guerra Mundial.

A produção dessas HQs possui várias fases: desde a produção norte-americana da década de 1940 até a produção por artistas brasileiros nas décadas de 1960 a 1990. As diferenças entre essa fases serão abordadas nesse trabalho como forma de analisarmos os diferentes enfoques sobre o Rio de Janeiro a partir de uma projeção internacional sobre a cidade, que ora a destacava como 'jóia do Atlântico', ora indicava a existência de uma 'outra cidade', onde pobreza e malandragem se conjugavam para freqüentar e colher as benesses da cidade dos cartões postais.

Se a criação do personagem se deu através do olhar estrangeiro, mais especificamente estadunidense, sobre o Brasil, num segundo momento iremos ver como a produção local foi 'abrasileirando' o personagem e trazendo às suas histórias diversos hábitos e comportamentos associados ao cotidiano do morador do Rio de Janeiro e além, do brasileiro urbano típico, notadamente os das classes mais populares que vivem em 'morros' e 'vilas', sambam, jogam futebol, têm dificuldades financeiras... histórias em que paisagens e locais da cidade do Rio de Janeiro são tanto pano de fundo quanto componentes do argumento.

\section{Yes, nós temos papagaios}

Surgido a partir da "Política da Boa Vizinhança" dos Estados Unidos com a América Latina no contexto da II Guerra Mundial (Rabelo, 2013, pp. 12-19), Zé Carioca foi um dos personagens criados nos dois filmes produzidos por Walt Disney como forma de estreitar os laços de amizade entre os países do continente, onde os filmes dos Estúdios Disney já tinham considerável repercussão, como a animação Fantasia, estrelada pelo 
camundongo Mickey Mouse, personagem símbolo dos estúdios, que alcançou grande repercussão no Brasil. (Leite, 1998 pp. 255-260)

Na revista $A$ Scena Muda, especializada em cinema, a visita de Walt Disney ganhou a capa da publicação, e é Pato Donald (curiosamente é a personagem Margarida que ilustra o texto) quem faz as honras de "apresentar meu pai Disney, a esta hora saboreando a feijoada brasileira e se inspirando em novos motivos da natureza deste país"2.

Se o objetivo principal da visita de Disney era claramente político, o declarado, além da amizade 'despretensiosa' entre América Latina e Estados Unidos, era a busca de inspiração por novos personagens. Ao final, o Brasil seria representado nos dois filmes surgidos desse tour: Alô, amigos (Saludos, Amigos) de 1942 e Você já foi a Bahia? (The tree caballeros), de 1943.

As razões para isso foram, além da forte receptividade no governo Vargas (tendo Oswaldo Aranha, ministro das Relações Exteriores, como expoente da ala pró estadunidense), o peso do Brasil no continente e sua localização estratégica como 'trampolim para África' e Europa, que deu origem à Base Aérea de Natal, Rio Grande do Norte, fazendo com que o país fosse alvo privilegiado da Política de Boa Vizinhança.

De certa forma, isso também respondia às críticas de que o intercâmbio cultural do Brasil com outros países era uma via de mão única. Logo no início do tour de Walt Disney ao Rio de Janeiro, o cronista Benjamin Costallat faz uma crítica velada ao sucesso de Walt Disney e da animação Fantasia:

\begin{abstract}
$\mathrm{O}$ sucesso dos artistas estrangeiros que aqui aportam deriva tanto de seus méritos, quanto, ou mais, de nossa excessiva cordialidade (...) É que, evidentemente, enquanto nós vivemos lhes prestando homenagens, mesmo através de alguns duvidosos valores, os públicos de outros países ainda não tomaram conhecimento de nossa existência como nação que, de há muito, já merece entrar no apreço alheio fora das estatísticas agrícola e de seu esmagador prestígio cafeeiro. O trabalho de nossa diplomacia deveria também se caminhar nessa direção. E mostrar ao mundo um Brasil que o mundo não conhece, e que, mesmo o Brasil , conhece muito pouco. (Costallat, 1941)
\end{abstract}

Em outro sentido, havia uma recomendação direta do Office of Inter-american Affairs (OCIAA), através da Motion Pictures, em que os laços culturais panamericanos

\footnotetext{
2‘Peço a palavra’ A Scena Muda. n. 1065. 19/08/1941
} 
deveriam ser aprofundados, reduzindo-se a influência do cinema europeu através de produções estadunidenses que utilizassem de atores e atrizes populares da América Latina, como Carmen Miranda e que as histórias fossem ambientadas em países latinoamericanos, especialmente Argentina, Brasil, Cuba e México. (Leite, 1998, p.15)

De modo que as duas produções atendiam as recomendações e abrandavam as queixas nacionalistas. Ambos os filmes eram a compilação de curtas de animação em que as histórias se passavam em cenários latinoamericanos, como Pateta encarnando um gaúcho, e/ou apresentavam como protagonistas personagens latinoamericanos: o mexicano Panchito (um galo com sombrero), um patagônico pinguim e ainda um pequeno avião que cruzava os Andes entre Chile e Argentina

No segundo filme, a carioca Aurora Miranda, cantora de rádio e irmã de Carmen Miranda, contracenou, numa mistura inédita até então de animação e atores reais, com os três personagens: Pato Donald, Panchito e Zé Carioca, consagrando assim a fraternidade panamericana com representantes dos gigantes do continente, respectivamente: Estados Unidos, México e Brasil.

Por outro lado, consagrava-se também o personagem brasileiro Zé Carioca, com jeito de malandro, cuja roupa e trejeitos foram criados a partir da junção de várias figuras reais: o sambista Paulo da Portela (escola de samba visitada por Walt Disney) (Pegoraro, 2012, p. 8); Manoel Vicente Alves, o Doutor Jacarandá, advogado que era um boêmio cheio de elegância e pompa. Por fim, um paulista de Jundiaí: o músico José de Oliveira Patrocínio, o Zezinho, que foi também o dublador nos dois filmes. Vale dizer que Zezinho desde a década de 1930 acompanhava as irmãs Carmem e Aurora Miranda em apresentações. (Pegoraro, 2012, p. 8)

Sucesso no cinema no Brasil e no mercado estadunidense, em outubro de 1942 Zé Carioca estreava em outra mídia: os quadrinhos, com uma tira semanal roteirizada por Hubie Karp e desenhada por Bob Grant, e a partir de abril de 1943 por Paul Murry, todos de nacionalidade estadunidense ${ }^{3}$. A tira José (Joe) Carioca foi distribuída pelo King

\footnotetext{
${ }^{3}$ Há uma pequena biografia dos autores, além de diversas outras informações, no sítio eletrônico especializado no universo Disney. Disponível em: http://coa.inducks.org/index.php. Acessado em: $08 / 09 / 2014$
} 
Features Sindycate até ser interrompida em outubro de 1944, quando foi substituída por outro componente dos três amigos: o mexicano Panchito. Essas tiras foram publicadas no Brasil a partir de 1945, através do Globo Juvenil (Pegoraro, 2012, p. 9). É sobre essa primeira visão do Rio de Janeiro, do Brasil e do cotidiano da pobreza na Cidade Maravilhosa que trataremos agora.

\section{'Um outro tipo de vida': Zé Carioca made in USA}

A aparição seminal de Zé Carioca se deu no filme Alô, Amigos! . Foi no episódio Aquarela do Brasil, em que fauna, flora e paisagens tropicais surgem ao som da voz e música de Ary Barroso, até que o papagaio surge à frente do Pato Donald para ciceroneálo num passeio pelo Rio: Pão de Açúcar, Cristo, Floresta da Tijuca, Urca, calçadão e a praia de Copacabana.

Se a iconografia do Rio exibida no filme partia de um olhar 'estrangeiro', que projetou a cidade para o mundo, este olhar era fruto de um movimento interno do Brasil de projetar a cidade como destino turístico internacional, tendo Copacabana com seus luxuosos hotéis e cassinos como pedra angular desse processo.

Essa estratégia vinha da década de 1930, em que as elites cariocas em conjunto com os políticos da capital da República intentavam a projeção do Rio, principalmente do seu litoral atlântico, como área de requinte, beleza e intensa vida cultural, digno de qualquer similar balneário europeu. De forma que a 'jóia do Atlântico' já teria sido o cenário da produção Flying down to Rio (dir. Thorton Freeland), de 1933.

De acordo com Julia O'Donnel, no entanto, "Os resultados desse esforço, no entanto, não foram exatamente aqueles desejados pela elite de Copacabana. Por mais que esta tentasse afirmar seu potencial turístico pela similaridade com outros balneários europeus, era a marca algo indiferenciada de um exotismo tropical que viria a ficar marcada no olhar estrangeiro." (O’Donnel, 2013, p. 185)

Sintomaticamente, logo na primeira tira em quadrinhos destaca-se outra característica marcante da cidade, como podemos ver nos recordatórios (as caixas de texto 
que contêm a narrativa da história) $)^{4}$ : "Rio de Janeiro, uma joia incrustada no Atlântico azul! Cidade de praias maravilhosas e arquitetura arrojada.../ Hotéis de luxo e finos restaurantes! Muita riqueza, luxos e romance!/Mas, como em todas as cidades, existe uma parte que leva outro tipo de vida." ${ }^{5}$ Nessa tira vemos no primeiro quadrinho o Pão de Açúcar, cartão postal da cidade; no segundo, o calçadão de Copacabana com seus restaurantes; e no terceiro, os famosos barracos da cidade, que convivem ao fundo com chaminés de fábricas e 'o outro tipo de vida'.

E é sobre as tentativas desse outro tipo de vida participar da sociedade de 'luxo e riqueza' que se desenvolve todo o enredo dessas primeiras tiras ${ }^{6}$. Para adentrar esse mundo, Zé Carioca não hesita em dar calotes, aplicar golpes, ao mesmo tempo em que seduzia jovens filhas de milionários. E quando surgem a personagem Rosinha e seu pai, Rocha Vaz, que até hoje são destaques na galeria de personagens de Zé Carioca. Zé Carioca se passa por milionário, empresário de artistas, guia na selva Amazônica...

Com exceção da tira de estreia, os cenários cariocas não compõem a história, embora fique claro que, na maior parte do tempo, ela se passa no Rio de Janeiro (a exceção é a expedição à Amazônia, com índios, onças e jacarés). Os teatros, restaurantes, hotéis e até o Jóquei Club não correspondem a cenários reais da cidade.

Mas a malandragem e a pouca ou nenhuma aptidão para o trabalho são características presentes no personagem nessa primeira fase, que Santos (2002) classifica como a fase americana, composta pelas tiras semanais e mais histórias fechadas ocasionais publicadas em gibis nos Estados Unidos e exportadas para outros países.

Podemos ver tais características, que irão acompanhá-lo por toda sua produção posterior, principalmente a brasileira, também na história Rei do Carnaval, com arte de

\footnotetext{
${ }^{4}$ Apresentaremos sempre a tradução para o português, quando for o caso de história produzida no exterior. Até porquê nossa argumentação se volta mais para a produção nacional e o seu contexto.

5"Como Almoçar de graça" Zé Carioca: 70 anos - volume 1. Ed. Abril, 2012. pp.12- 16

${ }^{6}$ Que vão da página 12 a 158 de Zé Carioca: 70 anos - volume 1. Ed. Abril, 2012. A maior parte delas já fora publicadas pela Editora Abril anteriormente, embora nessa edição a Editora diz se manter o mais fiel possível ao original.
} 
Carl Buettner, publicada ainda em $1942^{7}$. A diferença na história do gibi é que Zé Carioca não vive em um barraco, e sim dorme num banco de praça.

\section{Dos Estados Unidos ao Rio de Janeiro - via Argentina e São Paulo}

Além da produção estadunidense, nos anos seguintes Zé Carioca ganhou produções na Europa (Itália e Espanha) de histórias e figurinhas, embora seu papel fosse de coadjuvante e as histórias não fossem ambientadas no Rio (Santos, 2002, p. 43). O papagaio fazia sucesso em países latinos e, particularmente, no Brasil.

De modo que, em 1950, quando a Editora Abril é fundada, sua primeira publicação, a revista em quadrinhos $O$ Pato Donald (publicação mais longeva do Brasil, tendo sido publicada até junho de 2018) trazia em sua capa, além do famoso pato, o 'brasileiro’ Zé Carioca, como apelo de vendas e identificação com o público alvo. A capa foi ilustrada por Luis Destuet, argentino, que foi o autor das capas e das primeiras histórias Disney produzidas no Brasil a partir de 1951, inclusive as do Zé Carioca.

Assim, embora o personagem estampasse as capas desses primeiros números da revista, as histórias eram produções originais dos Estados Unidos com Pato Donald, os sobrinhos e seu Tio Patinhas, Mickey, Pateta, Lobão e Lobinho, entre outros.

Foi somente no número 22 que Zé Carioca faz sua estreia em uma história da Abril, com a aventura "Donald Fazendeiro", de Luis Destuet. Pato Donald recebe o convite de um tio para lhe auxiliar numa fazenda de café no Brasil, que tinha como secretário Zé Carioca $^{8}$. É o mesmo mote, um Zé Carioca ciceroneando Donald pelo território brasileiro, de "Zé Carioca na Amazônia", publicada em 1955. ${ }^{9}$

Nas mãos de Luis Destuet, entretanto, Zé Carioca perde as primeiras características de malandragem e vadiagem da fase americana. Da mesma forma, o Rio de Janeiro ou

\footnotetext{
7“O Rei do Carnaval” Zé Carioca: 70 anos - volume 1. Ed. Abril, 2012. pp.162- 173

${ }^{8}$ Ver http://coa.inducks.org/story.php?c=XA+EPD+308. Consultado em 11/09/2014.

${ }^{9}$ Mickey n 38. Ed. Abril, novembro de 1955. Ver http://coa.inducks.org/story.php?c=BC+MK+++38. Consultado em 11/09/2014
} 
qualquer de seus elementos a ele associado não fazem parte das histórias. Em "A Volta do Zé Carioca”, publicada originalmente em 1955, por exemplo, Zé Carioca abre uma loja de instrumentos musicais e convida os amigos para virem à inauguração, avisandoos que os esperará no 'Aeroporto de Congonhas'. ${ }^{10}$

Esse Zé Carioca 'trabalhador' e 'correto' será mantido também nas primeiras histórias escritas por brasileiros, principalmente, as primeiras do paulista Jorge Kato, que foi o autor de "Papai Noel por Acaso", de dezembro de 1959 (publicada em O Pato Donald n. 424), e de outra história também chamada de "A Volta de Zé Carioca", de março de $1960^{11}$. Nessa segunda, repetindo a primeira tira do personagem em 1942, no primeiro quadro aparece a imagem típica do Rio de Janeiro, com o Pão de Açúcar e o Cristo Redentor, com Zé chegando dos Estados Unidos de avião.

Nestas histórias o personagem não possui traços marcantes que o diferenciassem de outros personagens Disney. De modo que, ao começar a circular em revista própria a partir de janeiro de 1961, com Zé Carioca alternando semanalmente com O Pato Donald (o que fez que sua revista começasse no número 479), algumas das histórias eram meras adaptações de aventuras do Mickey ou do Pato Donald, com esses personagens sendo substituídos pelo papagaio, que ganhou os sobrinhos Zico e Zeca (substituindo os sobrinhos originais) como coadjuvantes nas histórias. Assim, as histórias apresentavam um Zé Carioca detetive ou ajudando o Tio Patinhas em algum empreendimento pelo mundo.

Enquanto as histórias adaptadas têm cenários tipicamente estadunidenses, com o Zé em aventuras pelo 'Velho Oeste' ${ }^{12}$ ou em 'feiras mundiais' ${ }^{13}$, cenários ligados às aventuras de Mickey ou Donald, as primeiras produções nacionais regulares se caracterizam pelos cenários paulistas, tais como o Estádio do Pacaembú ou o Parque do

\footnotetext{
${ }^{10}$ Pato Donald n 165. Ed. Abril, janeiro de 1955. Ver http://coa.inducks.org/story.php?c=B+PD++165-D Consultado em 11/09/2014

${ }^{11}$ O Pato Donald n. 434. Ed. Abril, março de 1960. Ver http://coa.inducks.org/story.php?c=B+PD++434-C. Consultado em 11/09/2014

12“"Os cavalos fujões" Zé Carioca n. 565 (setembro de 1962) pp. 3-12

13“Feira de Confusões" Zé Carioca n. 577 (novembro de 1962) pp. 3-12
} 
Ibirapuera, de modo que a cidade do Rio praticamente não aparece na assim chamada fase de adaptação (Santos, 2002).

Mesmo nas histórias originais de Kato, quando vemos que alguns elementos relacionados à cultura brasileira vão sendo incorporados ${ }^{14}$, a história se passa em local indeterminado, dando a entender que pode se passar na fictícia Patópolis, famosa cidade das aventuras dos personagem mais clássicos. Em "Parque de diversões e irritações", Zé Carioca é responsável por angariar fundos para a escola de samba 'Vai levando'. No primeiro quadro da história vemos diversos 'figurantes' de feições negras ou tipicamente vestidos no arquétipo de sambista. Para cumprir sua tarefa Zé não hesita em recorrer a Tio Patinhas, indo à sua Caixa Forte, elemento bem característico das histórias relacionadas a Pato Donald. ${ }^{15}$

Em “O pandeiro mágico”, Zé Carioca não pode participar do desfile de Carnaval, agora pela escola 'Feiticeiros do Samba' (mostra da pouca caracterização do personagem), numa história em que o primeiro quadro mostra o Pão de Açúcar desenhado sem muito zelo. ${ }^{16}$

Com a entrada de Waldyr Igayara de Souza como roteirista e desenhista_ em companhia de Izomar Camargo_ existe uma maior adesão a temas brasileiros e bastante inseridos no contexto da época. Uma história emblemática desses artistas é "Um festival embananado", de 1968. A história retrata o período de auge dos festivais de música, quando Zé Carioca, na companhia de um amigo (a galeria de personagens ainda não havia sido criada) resolve fazer um festival 'no morro', para convencer o reticente amigo que a ideia poderia ser lucrativa (a história começa com Zé reclamando que está na 'dureza'). Zé diz: "Por que não? Os festivais estão na moda. Há festivais em todo lugar. Por que não um no morro também? Lá tem gente boa à beça" no fundo desse quadro, vê-se a subida do morro, com barracos e um morador tocando violão. ${ }^{17}$

\footnotetext{
${ }^{14}$ Elisio

15“Parque de diversões e irritações" Zé Carioca n. 515 (setembro de 1961) pp. 3-15

16“'O pandeiro mágico" Zé Carioca n. 523 (novembro de 1961) pp. 3-14

17“"Um festival embananado" Zé Carioca: 70 anos - volume 1. 2012. pp. 262- 268
} 
Mas será com a entrada de Carlos Edgard Herrero no final da década de 1960, e principalmente, das parcerias entre Renato Canini e Ivan Saidenberg no início da década seguinte que o Rio e a malandragem voltam definitivamente a compor o personagem, agora com um olhar brasileiro, retomando então a trilha das primeiras tiras de Zé Carioca.

Esses artistas usaram a 'outra cidade' como local de moradia do papagaio e suas constantes tentativas de 'melhorar de vida', não através do trabalho, mas de golpes e calotes em diversos cenários cariocas. Foi Canini que, por exemplo, aboliu os clássicos paletó, chapéu-panamá e gravata borboleta dos primeiros tempos do personagem e vestiulhe de leveza com uma camiseta branca e calças. Além disso, fixou a moradia de Zé Carioca na fictícia Vila Xurupita, dotadas de diversas características então atribuídas às favelas: o barraco, a pobreza de seus habitantes, a cor negra de personagens e figurantes, um time de futebol e uma escola de samba (vale dizer que outros artistas optaram por manter o visual tradicional).

Assim, o 'morro' e a favela ganham relevância fundamental nas histórias. Mais do que mero cenário, era o ambiente onde muitas histórias se desenrolam e/ou começam, construindo o universo de Zé Carioca naquela que é considerada por críticos e leitores a sua melhor fase, a de Assimilação (Santos, 2002). Nas histórias dessa fase, além de festas juninas, Carnaval, feijoada, futebol e do samba, são tratados temas como preconceito, especulação imobiliária, remoção...

Façamos então um pequeno interlúdio para compreender essas visões e estereótipos sobre as favelas cariocas que circulavam no Brasil das décadas de 1960 a 1980 e de que forma essas visões, e estigmas que pairavam sobre a favela, influenciaram Canini e os demais artistas.

\section{Visões e estigmas sobre as favelas nas décadas de 1960 e 1970}

Desse o seu surgimento em fins do século XIX, a favela é estigmatizada quanto à origem de seus moradores (étnica e/ou rural) e como local de violência, vadiagem, ignorância, malandragem, ambiente de construções precárias... A favela era a reificação 
dos próprios estigmas, em que um local que tenha todas ou a maior parte dessas características passa a ser descrito pela sociedade como uma 'favela'. (Brum, 2012 p. 40)

No decorrer da primeira metade do século $\mathrm{XX}$, as favelas cresceram em número, quantidade de moradores e presença na cena urbana. Ora sendo toleradas, ora sendo até incentivadas (Gonçalves, 2013, p. 74), e quase sempre combatidas, para alguns a favela era vista como uma patologia urbana cujas razões da existência são atribuídas aos favelados em si, afeitos a costumes exóticos e que não partilhavam os valores da civilização, entendida aqui como a cidade.

Em outra vertente, mais moderada, considerava-se que a favela era um fruto indesejado, mas inevitável, do intenso e rápido processo de urbanização vivido pelo Brasil. Isto figura de maneira clara no Censo das Favelas de 1949, da Prefeitura do então Distrito Federal, em que a favela é tida como: "Fenômeno característico do rápido crescimento contemporâneo dos centros urbanos em conseqüência da Revolução industrial." (Prefeitura do Distrito Federal, 1949. p.12)

Na década de 1960, período que a produção nacional dos quadrinhos Disney se intensifica, a favela tinha sua imagem consolidada como: "A presença no agregado urbano, contrastando com seus padrões de conforto e civilização, de indivíduos subnutridos, ignorantes e socialmente desajustados." (SAGMACS, 1960. p. 37)

O 'problema-favela' clamava, segundo autoridades e setores da sociedade por uma solução urgente. Tendo o número de habitante destas praticamente dobrado entre $1950 \mathrm{e}$ 1960, passando de cerca de 170 mil moradores, correspondendo a 7,2\% do total da população da cidade, para 335 mil, 10\% da população total (RIBERIRO; LAGO, 1991, p.5), cifras que alarmavam os que viam a favela como uma infestação na cidade que crescia sem controle. Através da imprensa, como vemos em reportagem do Jornal do Brasil, o crescimento das favelas é noticiado com certo alarde. A matéria afirma: "De Vigário Geral até a Barra da Tijuca, contudo, não há quem não saiba que as favelas estão crescendo." 18

\footnotetext{
18“Nova favela nasce livremente perto do Rebouças" Jornal do Brasil, 29/09/1968.
} 
Tal visão levará ao período por nós chamado em estudo anterior de 'Era das Remoções' (Brum, 2012 p. 51), em que o Estado executará, primeiro no período 1962 64, durante o governo de Carlos Lacerda na Guanabara, e depois no período 1968-1973, no governo de Negrão de Lima com forte presença do governo federal instaurado com o Golpe de 1964. Em 1968, com a criação da autarquia federal Coordenadoria de Habitação de Interesse Social da área Metropolitana (CHISAM), a política de segregação espacial da cidade tomou proporções inéditas, removendo os favelados das áreas centrais da cidade, particularmente na valorizada Zona Sul, e transferindo-os para terrenos vazios na periferia, a algumas dezenas de quilômetros do centro da cidade e de seus antigos empregos.

Para as autoridades à frente do programa, refletindo as percepções das favelas como algo exótico e como um problema, a favela carioca pode ter sido "lírica" anteriormente, com seu samba e poesia, mas perdera então esta característica, sendo considerada um ambiente de degradação humana:

\footnotetext{
Os últimos sambas que descem dos morros já não cantam a poesia. Refletem, apenas, a consciência que o favelado começa a tomar de sua condição de miséria e promiscuidade. Em outras favelas, localizadas em antigos alagados, nem a poesia, só a silenciosa estatística de crimes, doenças e degradação. Apenas a germinação de fatos atentatórios à dignidade humana (Governo da Guanabara, 1969. p. 22).
}

\section{O malandro do morro: a Vila Xurupita}

Ao tratarmos as visões sobre a favela refletidas nas HQs de Zé Carioca, compreendemos os quadrinhos como uma representação da realidade, ainda que por vezes fortemente estilizada. Assim, as HQs podem ser compreendidas como uma demonstração de visões de mundo e de um imaginário social, como fez Robert Darnton em "O Grande Massacre de Gatos" ao demonstrar o universo mental dos camponeses franceses e alemães a partir dos contos de fada. Através desses podemos ver que naquele universo sócio-cultural da Europa Ocidental dos séculos XVII e XVIII, a fome é um aspecto constante; a nobreza figura como um elemento superior (o sonho da pobre moça casar 
com um príncipe encantado); a gula como grave pecado, entre outras representações apreendidas através dos contos.

As histórias de Zé Carioca com autores que roteirizaram e desenharam temas extremamente contemporâneos e relacionados ao cotidiano das favelas demonstraram as visões que existiam sobre a favela, principalmente as que permeavam a classe média, extrato ao qual pertenciam esses artistas, e que eram reproduzidas em jornais, músicas, filmes, documentos do Estado... Vemos isso principalmente a partir da entrada de Renato Canini nos quadros da editora Abril. ${ }^{19}$

Assim, nessa fase, vemos que a cidade do Rio ganha maior dimensão como ambiente onde as histórias se desenrolam e, principalmente, a Vila Xurupita como arquétipo da favela carioca. Nessa fictícia vila, além de habitarem os principais personagens que irão compor o universo do Zé Carioca _o urubu Nestor, o pato de olhos verdes Afonsinho, Pedro Feijoada (de atribuída ancestralidade africana ${ }^{20}$ ) e a frequente presença da namorada rica Rosinha_ estruturam-se a escola de samba Unidos da Vila Xurupita $^{21}$, o Vila Xurupita Futebol Clube, a festa junina ${ }^{22}$, a feijoada ${ }^{23}$... diversos elementos tidos, embora não de modo exclusivo, como típicos das favelas.

Um exemplo dessa caracterização popular da favela ocorreu numa publicação em pleno auge da moda disco, quando é aberta uma discoteca na Vila Xurupita que esvazia a roda de samba, com Zé Carioca defendendo a valorização do samba: "Um cara do morro não resiste a uma boa batucada." 24

\footnotetext{
${ }^{19}$ Canini, cujo traço é bem característico e facilmente reconhecido, é maior expoente dessa fase, mas não o único. No entanto, como a Editora Abril não indicava os artistas das histórias nessa época, não podemos reconhecer de modo indubitável os outros argumentistas e desenhistas das HQs, no que optamos por analisar a produção do período mostrando as mediações do universo sócio-cultural desses artistas coletivamente. Até porque nos interessa mais mostrar a difusão dessas percepções.

${ }^{20} \mathrm{Na}$ história "O Pedrão é nosso", o personagem Pedrão é contratado por árabes para fazer feijoada no Oriente Médio (referência a ida de jogadores e técnicos de futebol para região). Zé Carioca faz uma mobilização nacional para não deixar isso acontecer e diz numa entrevista à TV "O Pedrão é uma figura quase lendária ligada à história da feijoada em nosso país (...) Pra você ter uma idéia, foram os tataravós do Pedrão que trouxeram a feijoada da África pra cá." [vale dizer que nos interessa aqui mais a atribuição da origem africana à feijoada do que sua veracidade]. Zé Carioca n. 1627, janeiro de 1983, pp. 28-35.

21 "O sucessor" Zé Carioca n. 1423, fevereiro de 1979. pp. 3 - 9

22،"Zé Carioca e o Coroné Zé Buscapé” Zé Carioca n. 1649, junho de 1983 pp. 3 - 12

23“"O campeão da feijoada" Zé Carioca n. 1663, setembro de 1983 pp. 3 - 10

${ }^{244 " E m ~ r i t m o ~ d e ~ s a m b a ̃ o " ~ A l m a n q u e ~ D i s n e y ~ n . ~ 95, ~ a b r i l ~ d e ~ 1979 . ~ p p . ~ 35-39 ~}$
} 
Como dissemos anteriormente, esses elementos da fase de assimilação rompem com a trajetória anterior do personagem da figura do Zé Carioca trabalhador e até mesmo como um elemento de classe média. Numa das primeiras histórias da fase de adaptação, por exemplo, "Odisséia em Disneylândia", embora o mote fosse a fuga de Zé de um cobrador (traço a ser realçado na fase seguinte), quem abre a porta da casa 'escondendo' Zé Carioca é sua empregada negra de fala humilde: "Desculpe, sinhô. Mas o Seu Zé mando dizê para o sinhô que não está e para o sinhô passá no mês que vem..."25.

A noção da Vila Xurupita como morro se destaca na fase de assimilação. $\mathrm{Na}$ verdade, na primeira metade da década de 1970 há uma indefinição quanto ao local de moradia do personagem, ocorrendo algumas vezes de situá-lo no também fictício 'Morro do Papagaio'26. Com o passar do tempo, porém, a Vila Xurupita foi se consolidando nas histórias e, junto a isso, a descrição do local em que 'morro' e 'favela' eram tratados como sinônimos. Um exemplo disso foi "A Copa do Morro é nossa", publicada em meio ao Mundial de Futebol de 1982. Na história, o 'Vila Xurupita Futebol Clube' disputa o torneio enfrentando o time 'do outro lado do corrégo', desenhado como uma vala negra que divide a favela. Uma curiosidade é que a história faz alusão ao Corinthians como 'patrono' do time da Vila Xurupita.

Assim, vemos o constante uso do termo 'morro'_ com a respectiva caracterização de favela_ como ambiente das histórias através das referências que os personagens comumente fazem ("aqui no morro"), além, claro, da maneira como ela é ilustrada.

Nesse período, a Vila Xurupita tem uma arquitetura altamente irregular, com barracos à beira do abismo e precariamente equilibrados. Em "O sucessor", Zé Carioca e outros personagens aparecem à porta do barraco de Pedrão, feito de tábuas, tendo ao fundo vários barracos amontoados. ${ }^{27}$ Já na história “A noite dos zumbis”, Zé Carioca e Nestor andam em meio a construções precárias tendo todo o fundo do quadro repleto de barracos de madeira distribuídos de modo desordenado ${ }^{28}$. Ou ainda, a Vila Xurupita podia

\footnotetext{
25“Odisséia em Disneylândia” Zé Carioca n. 481, janeiro de 1961 pp. 3 - 12

${ }^{26}$ Vemos isso, por exemplo, na história "Agência Moleza de Investigação" Zé Carioca n. 1233, junho de 1975 , pp. 3 - 11

27“'O sucessor” Zé Carioca n. 1423, fevereiro de 1979. pp. 3 - 9

28“A noite dos Zumbis" Zé Carioca n. 1463, novembro de 1979. pp. 3-10
} 
ser caracterizada como à beira-mar, sem que o terreno deixasse de ser inclinado nos quadros, e com palafitas, emblemáticas da miséria da favela (especificamente a da Maré) no fim da década de 1970 , ao fundo. ${ }^{29}$

Mas a ideia de pobreza e irregularidade das moradias da favela não eram apenas o fundo da cena ou o ambiente das histórias. O ‘barraco' de Zé Carioca, embora não fosse desenhado uniformemente nas histórias, era caracterizado como apertado e/ou de material precário, podendo tanto figurar pendurado em um barranco, sendo sustentado apenas por dois galhos de árvore ${ }^{30}$, quanto uma construção de quatro tábuas em cada lado, à beira do barranco ${ }^{31}$ ou ainda, tendo o teto com vários furos ${ }^{32}$. A ausência da rede de eletricidade para muitos moradores de favelas, que vigorou até que a empresa de energia Light, ainda estatal, fizesse um programa de eletrificação de favelas em 1981 (OLIVEIRA et alii, 1993. P. 45), foi mostrada numa história de uma só página em que Zé, após ganhar um rádio, se desloca com uma enorme extensão até o vizinho para perguntar se podia usar a tomada. $^{33}$

Vimos que essa imagem da pobreza e precariedade era largamente difundida no período, servindo como principal argumento para o programa remocionista executado pelo Estado na virada das décadas de 1960/70 (Brum, 2012). Emblematicamente, o tema da remoção ligado ao da especulação imobiliária é tratado em algumas histórias desse período, sendo a ausência de propriedade por parte dos moradores uma das descrições da favela mais presente e a razão pela qual em várias histórias os moradores da Vila Xurupita são ameaçados de 'remoção’' (termo que não é utilizado nas histórias).

Numa história publicada em 1977, Zé Carioca vende aos moradores da Vila Xurupita apartamentos no 'Chatô Xurupitê', no que dois personagens sem identificação conversam no quadro ao verem o anúncio: "Xi, vai ser um espigão!"_ "A exploração imobiliária chegou à Vila Xurupita!”. O 'espigão', na verdade não passou de uma malandragem do personagem principal, sendo apenas cinco barracos em cima do outro

\footnotetext{
29“"Eugênio, o gênio" Zé Carioca n. 1415, dezembro de 1978. pp. 3-12

30“O grande prêmio de Vila Xurupita” Zé Carioca n. 1281, maio de 1976. pp. 3-13

31 “O técnico que veio de longe" Zé Carioca n. 1445, julho de 1979. pp. 3-11

32"Tem buraco no telhado" Zé Carioca n. 1465, dezembro de 1979. pp. 3-8

33“"Vizinho é pra essas coisas" Zé Carioca n. 1399, setembro de 1978. p. 21
} 
(uma antecipação da verticalização das favelas nas décadas posteriores). ${ }^{34} \mathrm{Em}$ "O 'bum' imobiliário", publicada meses depois, Zé Carioca recebe a visita de um falso funcionário da prefeitura avisando que seu barraco será demolido para dar passagem a um viaduto, fato comum na época, em que a Rocinha, por exemplo, teve parte removida para dar passagem à auto-estrada Lagoa-Barra. ${ }^{35}$

Percebemos uma inflexão nas histórias ao final da década de 1970, em que gradualmente o morro/favela sai das histórias e a Vila Xurupita vai ganhando características físicas de um bairro simples, similar ao subúrbio, embora ela nunca sido declaradamente localizada nele. A saída de Renato Canini, que tivera grande importância na caracterização dos anos anteriores (Santos, 2002, p. 65) dos quadros da editora é elemento e sintoma dessa inflexão.

Os barracos e a irregularidade do terreno vão dando lugar a casas de alvenaria. Inclusive a moradia dos amigos e a do próprio Zé Carioca vão ganhando esses contornos, embora as HQs mantivessem os elementos atribuídos à cultura popular na Vila Xurupita. A vestimenta 'clássica' do personagem, de casaca, chapéu e gravata borboleta, voltou a ser usada de modo alternado à vestimenta mais informal.

Por outro lado, a tipificação da Vila Xurupita como favela parece ter sido algo tão marcante na caracterização do personagem que ela foi 'recuperada' em algumas histórias posteriores, já na década de 1980. De modo que, embora as HQs do personagem não possua cronologia, foram feitas referências à mudança de status da Vila Xurupita não sendo mais um 'morro'. A favela passou a ser tratada por alguns roteiristas como parte do passado do personagem.

Numa história que parece justificar a mudança, Zé Paulista chega de visita ao primo Zé Carioca e pergunta: "Faz tempo que eu queria saber uma coisa. Como é que você e seus amigos, tão duros, saíram dos barracos e vieram morar nessas casas?" A história retoma a localização dos barracos como sendo no "Morro do Papagaio", pois a Vila Xurupita continuava sendo o ambiente principal das HQs, embora não mais na condição

\footnotetext{
34“"A imobiliária do Zé” Zé Carioca n. 1329, abril de 1977. pp. 3-10

35“'O 'bum' imobiliário" Zé Carioca n. 1393, julho de 1978. pp. 3-10
} 
de favela. A explicação que o argumentista colocou, narrada por Zé Carioca ao incrédulo primo, é de que o morro foi posto abaixo para construção de um espigão (remetendo à ilegalidade da posse e da permanente ameaça de remoção que falamos anteriormente) o que fez com que Zé Carioca e sua turma ficassem sem cLuiz Antônio Machadoasa, abrigados sob um viaduto até um gênio fazer com que eles ganhassem na loteria e conseguissem comprar um conjunto de casas para morar. ${ }^{36}$

Em "Como mudar uma casa", a referência à moradia anterior na favela por parte do personagem ocorre a partir de uma foto descoberta pelos sobrinhos em que Zé Carioca empurra um barraco. Ao ser indagado sobre a foto, ele diz: "Ela me lembra uma passagem chata da minha vida! / Foi no tempo em que eu morava no morro..." ${ }^{27}$. O enredo trata de Zé que, cansado de subir o morro, quer levar seu barraco para baixo, desenhado como uma rústica construção acompanhada de vários outros barracos precariamente pendurados no morro.

Numa história comemorativa dos 40 anos do personagem que trataria de sua infância, o personagem como narrador de sua própria biografia conta aos sobrinhos: "Vivi num dos mais belos locais do Rio de Janeiro". Essa frase, num recordatório, era acompanhada da visão do Pão de Açúcar do alto do morro sendo visto por um Zé ainda bebê. No quadro seguinte, o recordatório complementa "Dependendo do ângulo do qual a gente olhava, é claro..." sendo esse ‘outro ângulo' os barracos da favela. ${ }^{38}$

A partir da produção de fim da década de 1970, o inverso do 'passado na favela' do personagem e da caracterização da Vila Xurupita como bairro pobre e 'não-favela' se mostra, entre vários elementos, na ilustração da moradia de Zé Carioca como uma casa de alvenaria às vezes simples, de poucos móveis, ou como uma casa mais decorada e conservada $^{39}$. A 'nova' casa de Zé chega a ter quintal, onde a preguiça característica do

\footnotetext{
36“"Esse cara é um gênio" Zé Carioca n. 1583, março de 1982. pp. 3-11

37"Como mudar uma casa" Zé Carioca n. 1581, fevereiro de 1982. pp. 3-9

38“"A infância do Zé Carioca" Zé Carioca n. 1589, abril de 1982. pp. 3-12

39“"O pingüim do papagaio", Zé Carioca 1751, maio de 1985. pp 3-10; “Zé Baiano" Zé Carioca 1531, março de 1981, pp. 3-9.
} 
personagem passou a ser acompanhada de uma rede entre duas árvores que, não de modo uniforme, passam a ter presença frequente nas HQs. ${ }^{40}$

Vale dizer que as favelas do Rio também passam nesse período por intensas transformações. Fracassado o programa remocionista da década de 1970 pela inadimplência dos removidos, a 'favelização' dos conjuntos e a abertura da Barra da Tijuca como alternativa à expansão imobiliária, as favelas cariocas se tornaram uma permanência crescente em número e população.

De modo que o Estado, em todos os níveis, passou a ter a urbanização de favelas como política, de modo que a implementação de uma mínima infraestrutura e a garantia da posse (com o Estado abandonando, até então a ideia da remoção) fez com que as favelas passassem por uma revolução silenciosa no decorrer da década de 1980 em que o barraco de madeira e demais materiais precários, típicos de quem não sabia até quando permaneceria no local, passou a dar lugar a casas de alvenaria e que progressivamente vão assumindo características das habitações da classe média, processo intensificado nas décadas seguintes (OLIVEIRA et alii, 1993; Brum, 2012). Também se intensificou também nas favelas um processo de maior heterogeneidade entre moradores e 'partes' das favelas.

Isso é visto de modo claro numa história de 1983, em que o primeiro quadro é um plano da Vila Xurupita deserta em que as casas de alvenaria aparecem em primeiro plano, estando ao fundo casas mais simples de madeiras situadas em encostas logo atrás das primeiras. ${ }^{41}$ Em "Às voltas como Beijoqueiro" (referência à folclórica figura da década de 1980), Zé Carioca anda numa Vila Xurupita em que pequenas escarpas ao fundo têm barracos de madeira, em contraste com a casa de alvenaria em que mora o papagaio. ${ }^{42}$

Deste modo, não sabemos se foi uma intenção clara dos artistas sobre as mudanças que ocorriam nas favelas ao ilustrarem uma Vila Xurupita, ainda que não mais como favela e que agora seja plana, que continuava a ter barracos no fundo do quadro em várias

\footnotetext{
40“O jurado assustado", Zé Carioca 1925 janeiro de 1992. pp 3-10; "Professor de malandragem" Zé Carioca 1816, novembro de 1987, pp. 3-10.” ;“O táxi do Zé” Zé Carioca 1531, março de 1981, pp. 3-9. 41"O Dia do Sinistro", Zé Carioca 1653, julho de 1983. pp 3-10

42“"Às voltas com o Beijoqueiro”, Zé Carioca 1721, outubro de 1984. pp 3-10
} 
histórias, existindo similaridade com as favelas reais que têm 'partes melhores', mais próximas do 'asfalto', ou seja, da cidade formal, ladeadas com partes mais pobres e precárias.

A possível 'melhora' de vida do personagem, e num certo sentido a 'urbanização' da Vila Xurupita, provavelmente um ajuste ao 'padrão Disney', não significou que Zé Carioca estivesse finalmente rico ou integrado à parte mais nobre do Rio de Janeiro, característica seminal do personagem mantida na maior parte de sua trajetória desde Hollywood.

A 'distância' dessa cidade e os preconceitos comuns por parte dos cariocas moradores de seu litoral atlântico, mais especificamente da Zona Sul (a Barra da Tijuca ainda dava seus primeiros passos como sonho de consumo por parte das classes média e alta nas décadas de 1970 e 1980) em relação aos moradores dos subúrbios (e das favelas) é retratada em duas histórias distantes sete anos no tempo e em locais de moradia diferentes por parte dos personagens.

A primeira, ainda nos tempos da arquitetura irregular do morro que ilustra o primeiro quadro, em que ainda tem como título da história o termo pejorativo com que a classe média carioca tratava os que considerava 'invasores' das praias localizadas em seus bairros: "Zé Farofeiro" (o termo vem do fato das famílias que vêm de locais distantes levarem o almoço pronto para praia). Nessa HQ, Zé e os amigos combinam um piquenique na praia e descem o morro, tendo a praia ao fundo, em que são sucessivamente expulsos praia após praia. ${ }^{43}$

Na segunda história, já mostrando a casa de alvenaria, o personagem chega na praia após uma longa caminhada com o sol se pondo e reclama com Nestor "Toda vez é isso! Por que colocaram a praia tão longe da minha casa?" Nestor retruca: "Você é que colocou sua casa longe da praia!" A solução de Zé, fracassada, foi levar a casa inteira para a praia, sob resistência de um policial. ${ }^{44}$

\footnotetext{
43“Zé farofeiro" Zé Carioca 1429, março de 1979. pp 3-10

44"Eu quero uma casa na praia", Zé Carioca 1721, janeiro de 1986. pp 3-10
} 
Na década de 1990 o personagem passou por mais uma atualização, dessa vez junto com sua galeria, que passam a usar um visual mais colorido, com bonés, bermudas e camisas estampadas, aproximando-se da indumentária usada por jovens das periferias do Rio e São Paulo. Inclusive sem manter uniformidade típica das HQs, mantendo apenas o padrão das roupas e as características do personagem consolidadas nas duas décadas anteriores. No começo de 2000, a Abril fecha seu núcleo de produção de HQs e os artistas passam a trabalhar em estúdios terceirizados, com a produção nacional de quadrinhos Disney praticamente se encerrando, tendo apenas alguns artistas produzindo ocasionalmente histórias do Zé Carioca. A última desse ciclo foi "Zé das Selvas", publicada em outubro de $2000 .{ }^{45}$

Após isso, algumas histórias do Zé foram produzidas na Holanda e Estados Unidos, principalmente por Don Rosa, que desconsiderou a produção brasileira e retomou o Zé Carioca de Os Três Amigos, inclusive no roteiro, com um Zé Carioca que trabalha como cantor num balneário mexicano e acaba servindo de guia aos outros dois amigos numa viagem ao Brasil, com cenários cariocas que Don Rosa usa para ilustrar as HQs remetendo à década de 1940 .

A produção brasileira pela Editora Abril seria retomada em 2012, mais de uma década depois, no volume 2 da edição de comemoração dos 70 anos do personagem, de 2102, com duas histórias que mantiveram o visual criado nos anos 1990: uma história de dois jovens artistas estreantes, Fernando Ventura e Diego Munhoz (arte-final) e outra de dois veteranos que já fizeram juntos 64 HQs: Arthur Faria Júnior e Luiz Podavin.

A partir daí, a Abril manteve a produção regular de HQs do Zé Carioca, embora não no ritmo das décadas anteriores, com o personagem mantendo os traços da malandragem, preguiça, futebol e samba que guiaram a produção nacional a partir do auge da década de 1970.

45“Zé das Selvas” Zé Carioca n. 2165, outubro de 2000. pp 3-9. 


\section{Conclusão}

Embora seja uma criação estadunidense e os Estúdios Disney nos Estados Unidos tenham mantido uma produção intensa dos quadrinhos, a produção em outros países, dentre eles o Brasil, dotou os personagens de cores locais, como pode ser percebido nas HQs italianas, dinamarquesas, holandesas... com temas e paisagens característicos desses países.

No Brasil, com um personagem 'brasileiro', isso foi potencializado. O Zé Carioca estadunidense foi 'comido', no sentido antropofágico defendido pelo modernista Oswald de Andrade, para quem "a antropofagia não é apenas deglutição de elementos externos à cultura brasileira mas também valorização desta, especialmente em sua vertente popular" (Souza, 2007.p 120).

Foi justamente a caracterização do Zé Carioca do morro, preguiçoso, malandro, apreciador do futebol e do samba que tornou o personagem sucesso de vendas no Brasil, com a revista se tornando quinzenal entre as décadas de 1970 e 1980. Entre os Anos de Chumbo e o fim da década de 1990, Zé Carioca vivenciou os contrastes dos brasileiros, da torcida pela seleção na Copa, da venda de jogadores para o exterior ou da ameaça a perda do 'campo de pelada' para a especulação imobiliária; se endividou, cantou, sambou, perdeu casa, foi 'removido', morava 'longe'...

O discurso tão presente no imaginário carioca de uma "cidade partida", termo consagrado no livro do jornalista Zuenir Ventura (1994) que indica a coexistência de duas cidades, grosso modo, uma próspera e civilizada e outra atrasada e inculta... Classificação à qual não concordamos, mas o que nos interessa mais aqui é o fato dessa percepção estar presente nas descrições da cidade nos mais variados campos da cultura, dos quais as Histórias em Quadrinhos são um deles.

Essa dualidade foi o fio condutor de toda a trajetória do personagem em que Zé Carioca tenta se inserir na parte próspera com o menor esforço possível, através de planos mirabolantes e golpes, encontrando permanente resistência. Em muitas histórias ele vai parar na delegacia e as dívidas do personagem deram origem à criação dos personagens 
"Anacozeca" (Associação Nacional dos Cobradores do Zé Carioca) que participaram de diversas histórias em que o mote era a cobrança das suas dívidas.

Símbolo maior dessa dualidade é Rosinha, eterna namorada de Zé Carioca, e seu pai, o milionário Rocha Vaz, que surgiram nas primeiras tiras estadunidenses e foram mantidos, em outros moldes, na produção brasileira. Rocha Vaz tem horror ao 'genro' e em várias histórias tenta separar o casal, considerando-o folgado, vagabundo, preguiçoso, que só queria saber de samba e futebol... em outro sentido, esse embate destacava uma imagem do povo feita pelas classes médias e altas.

A história "Lobo em pele de cordeiro" demonstra isso através de uma inversão de papéis entre Zé Carioca e Rocha Vaz. No começo da história, Rocha Vaz abandona o terno característico e veste camisa e boné, se aproximando com uma cuíca de uma roda de samba composta pela turma do Zé, marcando uma 'pelada' no dia seguinte. Zé Carioca não entende o que mudou no comportamento do sogro que passa até a ser chamado de 'Vavá'. No fim, o sogro queria ganhar a confiança dos amigos de Zé para comprar o terreno do Vila Xurupita Futebol Clube para construir um shopping. Vemos os elementos tidos como populares sendo apropriados pela elite, representada por Rocha Vaz. Ainda, é Rocha Vaz que usa justamente a malandragem, o engodo, o subterfúgio para conseguir alcançar seus objetivos.

As Histórias em Quadrinhos, através do lúdico, da ficção e do fantástico, são representações de uma realidade tal com percebida pelos seus contemporâneos. A produção brasileira de Zé Carioca, principalmente entre as décadas de 1970 e 1990 mostraram, de forma leve e humorada, e nem sempre inocente, experiências e dramas reais de milhões de brasileiros que vivem nas 'Vilas Xurupitas' de todo o Brasil.

\section{Referências:}

BRUM, Mario. Cidade Alta. Rio de Janeiro: Ponteio, 2012.

CHISAM. Metas alcançadas e novos objetivos do programa. Rio de Janeiro: BNH / Ministério do Interior, 1971. 
COSTALLAT, Benajmin. “A desconhecida reciprocidade” Jornal do Brasil 22/08/1941

GOVERNO DA GUANABARA. Rio: Operação Favela. Rio de Janeiro, 1969.

GONÇALVES, Rafael Soares. Favelas do Rio de Janeiro. História e Direito, Rio de Janeiro: Pallas/PUC, 2013.

LEITE, Sidney Ferreira. O filme que não passou: Estados Unidos e Brasil na Política da Boa Vizinhança - a diplomacia através do cinema. Tese de Doutorado em História Social. Universidade de São Paulo. São Paulo, USP, 1998.

O'DONNEL, Julia. A invenção de Copacabana: culturas urbanas e estilo de vida no Rio de Janeiro. Rio de Janeiro: Zahar, 2013.

OLIVEIRA, Anazir Maria de; et alli. Favelas e organizações comunitárias. Petrópolis: Ed. Vozes, 1993

PEGORARO, Celbi. “A criação do Zé Carioca” Zé Carioca: 70 anos - volume 1. Ed. Abril, 2012. p.3-8

PREFEITURA DO DISTRITO FEDERAL. Censo das favelas: Aspectos gerais. Rio de Janeiro: Secretaria Geral do Interior e Segurança, Departamento de Geografia e Estatística, 1949.

RABELO, Fernanda Lima. O outro lado de Hollywood: o cinema documentário e a inserção cultural norte-americana no Brasil durante a Segunda Guerra Mundial. Rio de Janeiro, Dissertação de Mestrado em História Social. Rio de Janeiro: UFRJ, 2006.

RIBEIRO, Luís César Queiroz \& LAGO, Luciana Correa do; “Transformação das metrópoles brasileiras: algumas hipóteses de pesquisas." Trabalho apresentado ao XV Encontro Anual da ANPOCS, Caxambu, 1991

SAGMACS. Aspectos Humanos da Favela Carioca. São Paulo: SAGMACS, 1960

SANTOS, Roberto Elísio dos. Para Reler os Quadrinhos Disney. Rio de Janeiro: Paulinas, 2002.

SOUZA, Ricardo Luiz de. "Ruptura e incorporação: a utopia antropofágica de Oswald de Andrade" Scripta, Belo Horizonte, v. 11, n. 20, p.113-126, $1^{\circ}$ sem. 2007. 